\title{
Multilevel Practical Teaching System Based on the Excellent Engineers Education Mode
}

\author{
Bin Zheng ${ }^{1, a}$, Yongqi Liu ${ }^{1, b}$, Daichang Guo ${ }^{1, c}$ and Peng Sun ${ }^{1, d}$ \\ ${ }^{1}$ School of Transportation and Vehicle Engineering, Shandong University of Technology, Zibo \\ 255049, China. \\ asdutzb@163.com, bsdutliu@163.com, 'c1025521252@qq.com, 'zllsunpeng@sina.com
}

Keywords: Practical teaching system; excellent engineers education; multilevel; innovation.

\begin{abstract}
The basic task of excellent engineers education mode is to cultivate the practice-oriented advanced professional personnel with innovative spirit and practical ability. The practical education is the most effective way to cultivate students' creativity. In order to enable students to have the ability of engineering practice and innovation that is demanded in society, a multilevel practical teaching system with "one core, two bases, four levels", a system of the corresponding curricula standards and training quality evaluation, and the guidance team and practical platforms are constructed.
\end{abstract}

\section{Introduction}

In the past twenty years, the engineering education of developed countries in the world has gradually integrated technology and science orientation. The engineering education is performed in more than 900 colleges and universities which accounts for 1/3 in U.S.A. There are a large number of well-known colleges and universities to implement the engineering education model in Europe, especially in Germany and France. The only way for engineering education in China is innovative and to build engineering education with Chinese model innovatively, because the stage of engineering education and national mission in our country are different from developed countries in the west[1-3].

The Ministry of Education led the implementation of the "excellent engineer education and training program" in 2010. The aims of the program is to reform and innovate the training mode of engineering education, create new mechanism of personnel training based on universities and enterprises joint, and focus on improving students' sense of social responsibility to serve the country and the people, spirit of innovation to explore, and practical ability of solving problems. In 2013, the major of energy and power engineering in Shandong University of Technology was selected into the program of "The pilot majors of provincial excellent engineer education and training program" performed in Shandong Province.

The core and the key of "excellent engineer education" is to cultivate the ability of engineering practice and innovation of students. The training of practical ability mainly depends on the practical teaching system[4-6]. An excellent practical teaching system is the key to ensure the personnel excellent engineers training in high quality. Whether practical teaching system is scientific, reasonable and practical will directly affect the ability of college students' engineering practice and innovation. The present practical teaching system is hard to meet the requirements of personnel training of the excellent engineers, due to some common problems, such as the lack of combinations of practice and engineering application, education of vocational ideology, enthusiasm of enterprises to cultivate. It is impossible to cultivate the high level, high ability and high quality practice-oriented advanced professional personnel with characteristics of "generous, compound, open and innovative", unless construct a new practical teaching system in energy and power engineering with the cores of training students' abilities of engineering practice, engineering design, and engineering innovation. 


\section{Problems in Present Training System}

\subsection{The Lack of the Basic Idea of "Practical Education is the Key Component of the Training}

System”.

On the one hand, the functional departments or teachers in some universities regard curriculum design, graduation design, production practice, and graduation practice as the auxiliary work that is outside the classroom teaching. Some universities lack the participation of double-identity teachers who have rich experience in engineering, the overall design of practical teaching, and guidance and design of comprehensive and designed experiments. On the other hand, it is not enough for students to pay attention to practice. And they lack the initiative and enthusiasm when participation.

\subsection{The Lack of Construction of Practical Teaching Bases Outside School.}

The practical teaching bases outside school aimed to provide students with engineering practice environment in practice, graduation design, social practice, etc. which are essential prerequisite for engineering practical teaching. The bases generally are large and medium-sized enterprises with professional background and influence. However, some enterprises are not enthusiastic about arranging students' practice, even shirk form some excuses. Some enterprises are not willing to arrange practice. Even though students have arrived, it is hard to guarantee the quality of practice. Lack of supporting policies and stimulation of economic benefits is the reason for such cases.

\subsection{The Lack of Construction of Teaching Staff in Practical Teaching}

The energy and power engineering specialty is a major that requires higher ability of engineering practice. In excellent engineer training, it requires more for the ability of engineering practice. The practical teaching should develop with the theory teaching and the scientific research work synchronously, which requires that the teachers in colleges and universities should be not only familiar with theoretical knowledge but have rich engineering practice and scientific research experience. Nevertheless, although teachers in colleges and universities have higher educational background, teachers who have rich experience in engineering practice are less and less. At the same time, the number of teachers is insufficient. Student-teacher ratio has increased greatly. There is heavier burden on teachers. As mentioned above, teachers in colleges and universities cannot satisfy the requirement of excellent engineer education and training.

\section{Construction of Practical Teaching System and Supporting Resources}

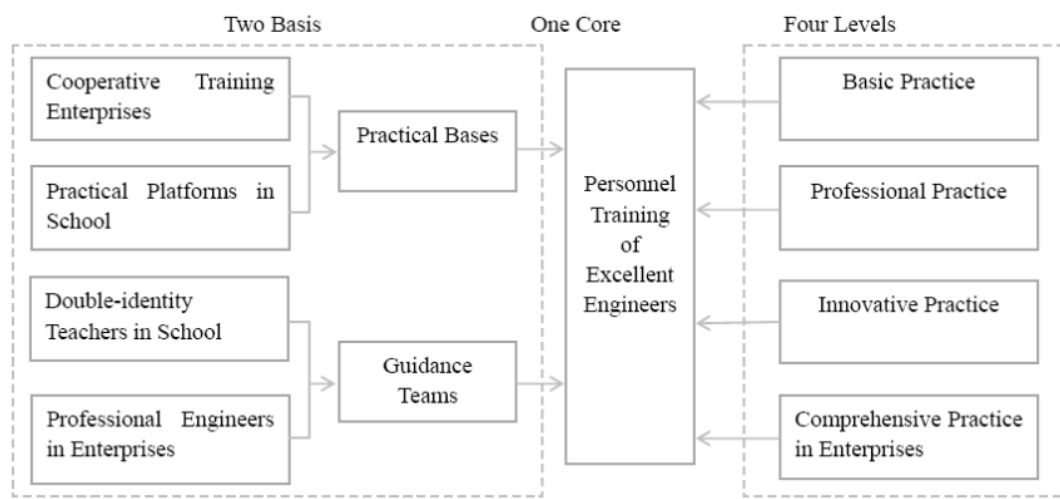

Fig. 1 Sketch of practical training system

\subsection{Construction of Multilevel Practical Teaching System.}

The aim of constructing multilevel practical teaching system of "one core, two bases, four level" for cultivating excellent engineers is to training students to have good ability of engineering practice and innovation. The structure of the system as shown in Fig. 1.

(1) One core is the ability of engineering practice and innovation as the core of training.

(2) Two basis, practical platforms and guidance team, are software and hardware conditions that support the normal operation of the system. The practical platforms include the practical teaching bases build in cooperative enterprises and all kinds of experimental and training laboratories. 
(3) Four levels mean the whole system is composed of the basic practice, professional practice, innovative practice and comprehensive practice in enterprises, which will be completed step by step.

(a) Basic practice: It includes the module of basic quality and experiment. The module of basic quality mainly consists of practical courses of the ideological and political theory, entrance education and military training, labor for public welfare, introduction of the subject, general education courses of innovation and entrepreneurship, etc. The module of experiment consists of all experiments in general education courses, professional basic courses, professional core courses, and professional optional courses. On the one hand, to cultivate students to establish the basic idea of "the ability of engineering practice and innovation is the base of survival”, and have good professional ethics, professional spirit, hard-working spirit, etc. On the other hand, to train students to master the operative and practical ability of the basic professional experiments, and the basic ability to analyze problems and solve problems. And to help students understand the professional theories better.

(b) Professional practice: It includes the module of engineering training and comprehensive practice. The module of engineering training, including some practical courses, such as engineering training, curriculum design of machine design and drawing of machine drawing, mainly relies on the college student training center to train students to master technical tools and processing methods and the basic ability of drawing. The module of comprehensive practice, including driving practice, cognition practice, disassembly and assembly practice of internal combustion engine and production practice of manufacturing technics of internal combustion engine, is mainly used to enhance the students' cognition of professional knowledge and skills, to cultivate students' ability of professional practice and solving practical problems.

(c) Innovative practice: It includes the module of social practice and scientific and technological innovation. The module of social practice is mainly based on social practice to have students understand the profession and related industries better, to ensure a proper occupational orientation, to be prepared well for jobs, and to strengthen their competition. The module of scientific and technological innovation relies on practical course of professional design and production, college student science and technology innovation projects and college students scientific and technological innovation competition to bring into play students' creative thinking and creative spirit, to consolidate and improve students' theoretical knowledge, to highlight the development of students” personality, and to improve students' ability to innovate.

(d) Comprehensive practice in enterprises: It includes the module of enterprise learning and engineering research and development(R\&D). The module of enterprise learning is performed by enterprise learning practice, including learning of standardization, learning of quality management system, visiting production lines, participating in process making and design, main technical specification and enterprise culture, etc. The module of engineering R\&D is performed by graduation practice, graduation design and graduation appraisal. Enterprise provides topic and content of graduation design to student based on the needs of R\&D department, characteristics of student, and present projects so that student can complete the graduation design when joining in the process of engineering $R \& D$, and truly integrate into the enterprise. Students can enhance the ability of engineering design and innovation by operation of practical projects.

\subsection{Establishment of the Curricula Standards of the Practical System and the Standards of the Quality Evaluation.}

Under the premise of fully absorbing the requirements of engineering personnel, the detailed curricula standards which highlight the dominant and leading position of enterprises, are made for the multilevel practical teaching system. In order to guarantee the quality of personnel training, the corresponding evaluation standards are made for all curricula, and the quality evaluation system with quality, practice, tutors in school and instructors in enterprises is established. Evaluation standards, mainly based on the evaluation of students' engineering ability, include elaborate scheme and details of examination and evaluation. According to the nature of different practice, the specific evaluation indicators are performed and quantified so that evaluation is scientific, impartial and operable. 


\subsection{Strengthen the Construction of Guidance Team.}

The construction of guidance team is focused on improving the ability of engineering practice and the ability of design and creation of engineering teaching staff, and effectively transforming the engineering practice experience to the quality of teaching resources.

(1) Improve the ability of engineering practical innovation of the professional teachers in school. On the one hand, because of strengthening cooperation on R\&D between school and enterprises, firstly, teachers who already have work experience in enterprises get more experience on work and engineering practice. Secondly, teachers who have certain experience on engineering practice get work experience in enterprises. Teachers can directly participate in the daily production and technology upgrading, transformation in enterprises by cooperating with enterprises on projects, completing the development of technology, and technical services, etc.. On the other hand, the way combined the intensive training with the long-term training is performed for teachers in the teaching staff who have insufficient or no experience in engineering practice. Firstly, send the teachers to correlative enterprises for 3 to 6 months to accumulate engineering practical experience, and kwon the production process, the engineering technology and the management well. Secondly, the long-term training of the "one to one" mutual help is carried out by inviting teachers who are experienced on engineering practice in school.

(2) Employ mentors from enterprises. The guiding idea of "corporate mentors are core" is performed in excellent engineers training, in which the corporate mentors play an important role. Firstly, employ corporate experts as part-time teachers to participate in practice in school. The coaching mode with compound team of "corporate mentors, professional tutors in practice center in school, and professional teachers” is applied. The teaching is carried out by case teaching, scene teaching, special topic lectures, and instruction of engineering practical technology, etc.. The engineering elements are integrated into teaching in advance so that students can possess some knowledge of engineering design and basic abilities before entering the enterprises. Secondly, the double-tutor mode of "mainly based on corporate mentors and assisted by professional teachers" is applied in comprehensive practice in enterprises. According to the actual situation of the enterprises, the corporate mentors will provide students instruction or on-site consultation for their production learning, and graduation design and implementation, and be in charge of the all-round basic training of professional training for engineers.

\subsection{Strengthen the Construction of Practical Platforms.}

The practical platform is basic to guarantee that the practical teaching runs smoothly. The systematic construction of practical platforms in school and in enterprises is carried out based on our major. The practical platforms are based on the national virtual simulation experiment and teaching center of vehicle engineering and transportation, the provincial higher school backbone subject teaching and experimental center of energy and power engineering, the engineering training center of Shandong university of technology, and the student innovation and entrepreneurship laboratory, etc.. The special funds are allotted to help students act innovative and entrepreneurial activities, and strengthen the investment of equipment, the standardized management of experiment and practice, the construction of comprehensive innovative experimental projects, and the management and instruction of innovative and entrepreneurial activities. In the construction of practical platforms in enterprises, the special education center of "excellent engineers training" is established, the management and operation of specialized personnel are set up, the special places and equipment of practice are constructed, enterprises senior or more technical staff and senior executives are hired to be corporate mentors, and the resources of engineering design and guidance team from enterprises are fully used, so that the task of comprehensive practice in enterprises is completely put into effect. 


\section{The Advantages of Multilevel Practical Teaching System}

Construction of practical teaching system with "one core, two basic, and four levels" can effectively improve students' engineering quality, and the ability of engineering practice, engineering design and engineering innovation. In this system, all practice in school is highly integrated with engineering practice. Not only can students fully understand the professional knowledge, but can master rich engineering applied knowledge in advance. The combination of theoretical knowledge and practical application is a good foundation for the rapid and thorough development of comprehensive practice in enterprises. Give full play to the leading role of enterprises, and guide the training by projects in the practice in enterprises. Through deeply participating in the development of projects, students can greatly enhance their ability of engineering quality and innovation.

A win-win model of cooperation between colleges and enterprises was formed by building the special practice education center of “excellent engineers training” closely combined with enterprises. Based on R\&D center in enterprises, the special practice education center of "excellent engineers training" was established, which fully plays the key role and the leading position of enterprises in the engineering personnel training. During practice, student can be really regarded as a member of enterprises. Not only can the practical teaching fully integrate into the process of engineering research and development, and guarantee the cultivation of students' ability of engineering design and innovation, but also can students become the fresh power for R\&D in enterprises, and promote the ability of the whole $R \& D$ and the construction of personnel staff. Students share the effective accomplishments they achieved with enterprises so that students and enterprises can benefit each other to achieve a win-win result between school and enterprises.

The quality evaluation system of excellent engineers training was established to guarantee the quality of training effectively. The quality evaluation system, regarding the evaluation of students' engineering ability as main body, which focuses on the comprehensive evaluation of students' engineering capability, organizational ability, team cooperate ability, interpersonal skills, and global vision, etc., is effective guarantee to enhance the quality of training.

\section{Conclusion}

Under the core ideas of "the education of excellent engineers", a multilevel practical teaching system with "one core, two basis, and four levels" which is applicable for the energy and power engineering specialty and a system of the corresponding curricula standards and training quality evaluation are constructed. At the same time, the construction of guidance team and practical platforms are reinforced so that students can be cultivated with high quality.

\section{Acknowledgment}

This research was supported by Shandong Province Excellent Engineers Education Projects and Shandong University of Technology Reform in Education Key Projects.

\section{References}

[1]. H. Polina, H. Victor, and O. Jivka, "Teaching methodology for virtual reality practical course in engineering education,” Procedia Computer Science, vol. 25, pp. 251-260, November 2013.

[2]. H. Zhu, Z.Y. Li, and Z.J. Liu, "Research and practice on higher engineering education reform and outstanding engineers cultivation,” Research in Higher Education of Engineering, pp. 69-72, May 2013. (In Chinese)

[3]. J.F. Zhang, and T.L. Huang, "The reform of the practice teaching of water \& wastewater engineering based on 'the outstanding engineers education and training plan'," Xi'an Univ. of Arch. Tech.(Social Science Edition), vol. 30, pp. 93-96, May 2011. (In Chinese) 
[4]. Y.L. Chen, and L.Wang, "Student satisfaction after the implementation of "excellence engineer training plan' in project 211 universities in Jiangshu province (PRC): an empirical research,” Modern University Education, pp. 65-68, June 2015. (In Chinese)

[5]. S.J. Chen, "Study and practice of education and training quality guarantee mechanism of outstanding engineers: a case study of nuclear power engineering specialty,” Value Engineering, vol. 33, pp. 303-304, August 2014. (In Chinese)

[6]. R. Zhang, "Exploration on the key issues of practical teaching reform of computer network," Energy Procedia, vol. 17, pp. 1914-1919, August 2012. 